\title{
Time to move on from shuttle, says astronaut
}

As Nature went to press, the space shuttle Discovery was poised for a 13 July launch in the first shuttle mission since Columbia burned up on re-entry in February 2003. NASA managers have done their best to fix the problems that led to the disaster, but the 21-year-old vehicle still faces significant risks.

Three-time shuttle astronaut George 'Pinky' Nelson had the unique experience of flying the missions immediately before and after the 1986 Challenger accident. An astrophysicist, he left NASA in 1989 and now directs the Science, Mathematics and Technology Education programme at Western Washington University in Bellingham. Nature asked him how it felt to be one of the first astronauts flying the shuttle after a disaster, and what he thinks of NASA's plans.

What was different about the first flight after the accident? Had your perception of the risk changed?

No. Actually, the flight before Challenger was really ragged. We had five launch attempts and all kinds of technical problems. You could see things weren't going well, but when you're in the cockpit, you just want to fly. The flight after Challenger, we knew that bad things can happen, but I felt that they had looked at everything twice and it was going to be a pretty safe mission. I was confident that if something got us, it wouldn't be the O-rings.

And it probably won't be debris striking the wing next time.

Yes, that was really a fluke. But there's no excuse for flying when they knew the O-rings were burning or before Columbia when they knew they were losing material off the external tank. I don't fault the engineers, I fault management. Falling debris is a problem that got them once, and if they haven't fixed it, they shouldn't be flying.

Do you think things have really changed with the shuttle programme?

No. The shuttle's a dangerous machine. It should have been put to bed ten years ago. I mean, it's a marvellous machine, but it never worked out to be the operational

need for what they're trying to do? They still have the skill mix for their initial fantasies about the shuttle and space station. I feel sorry for those guys - the world's most talented people just going to meetings, sweating, living in the world's worst climate [in Houston, Texas]. I don't know what I'd do if I were in their shoes. There are still interesting things for an astronaut to do, though. Building the space station's got to be a great mission. And servicing the Hubble Space Telescope I think [NASA administrator Michael] Griffin will make a good call on that.

\section{What is the right call?}

If you're going to fly the shuttle at all, you ought to service the space telescope. Here's something you can do to contribute to science it's got to be the number one priority. I had no respect for [former administrator Sean] O'Keefe's decision-making on that. He got burned by Columbia, and was trying to get rid of every mission he could. I don't think he realized NASA was an agency that actually did things.

\section{Can NASA be revitalized?}

I don't know. Right now, NASA is getting by on inertia. There are NASA centres all over the country, money's being spent and Blast from the past: George Nelson knows the shuttle's dangers.

spacecraft that they hoped it would be, and they should have moved on.

Are you happy with plans to build a Crew Exploration Vehicle for the Moon and Mars? Yeah, I don't think much of the space station, and it will be nice to have another vehicle.

The station is a marvellous engineering achievement, but it was sold as something else. There's no science being done. If anything, they should have built a platform around the Moon or somewhere interesting.

What about the current astronaut corps? There aren't many flight opportunities, but there are around 100 active astronauts. That's something NASA should think hard about. How many astronauts do they really the aerospace industry needs to employ people - that's what's driving it all. They have no mission, like saving the world from Communism or whatever else has driven the space programme in the past. I would like to see the Moon-Mars exploration programme happen. But we're spending a lot of money blowing up stucco in Iraq. It's hard to send aluminium into space when you're sending bricks and mortar 50 feet up.

You're focusing on education these days. Has space exploration lost its unique ability to inspire schoolchildren?

I think so, although science is still a motivator. Space has its place, but it isn't necessarily what everyone wants to do any more.

Interview by Tony Reichhardt

\section{.}

